\title{
Vertical wind profiles over an urban area
}

\author{
STEFAN EMEIS*
}

Institute for Meteorology and Climate Research, Forschungszentrum Karlsruhe GmbH, Germany

(Manuscript received December 14, 2003; in revised form March 2, 2004; accepted March 29, 2004)

\begin{abstract}
Long-term measurements of wind and turbulence profiles over urban areas from acoustic remote sensing have not been available so far. 17 months of Doppler-SODAR measurements in the town of Hannover, Germany, are evaluated here with respect to mean wind speed, variance of the vertical velocity component, and turbulence intensity for heights up to $210 \mathrm{~m}$ agl. The resulting monthly means show that all vertical profiles are influenced by the high roughness and by the thermal properties of the urban surface. Main features are a missing diurnal course of the wind speed a few tens of meters above mean roof-top level and variances that increase considerably with height not only during daytime but also in many nights. While the first feature is typical for boundary-layers over rough surfaces, the second feature is only explainable by the larger heat input into the urban boundary-layer from the surface below. It is proposed to rely more on vertical remote sensing than on the vertical extrapolation of Prandtl-layer similarity theories when assessing the vertical structure of an urban boundary-layer.
\end{abstract}

\begin{abstract}
Zusammenfassung
Langfristige SODAR-Messungen von Wind- und Turbulenzprofilen über städtischen Gebieten lagen bisher nicht vor. Hier werden nun Auswertungen von Doppler-SODAR-Messungen aus Hannover bezüglich mittlerer Windgeschwindigkeit, der Varianz der vertikalen Geschwindigkeitskomponente und der Turbulenzintensität bis in 210 m Höhe über Grund aus einer 17 Monate dauernden Kampagne vorgestellt. Die sich ergebenen mittleren Profile zeigen klar den Einfluss der hohen Rauhigkeit und der thermischen Eigenschaften einer städtischen Oberfläche. Auffallend sind insbesondere der fehlende Tagesgang der Windgeschwindigkeit in einigen zehn Metern Höhe über Dachniveau und Varianzen, die nicht nur tagsüber sondern teilweise auch nachts noch mit der Höhe zunehmen. Während das erste Phänomen typisch für rauhe Oberflächen ist, ist das zweite nur durch den größeren Wärmeeintrag von unten in die städtische Grenzschicht erklärbar. Die Studie legt nahe, sich bei der Ableitung der vertikalen Struktur der urbanen Grenzschicht stärker auf Fernerkundungsmessungen als auf die vertikale Extrapolation von Ähnlichkeitsgesetzen der Prandtl-Schicht zu stützen.
\end{abstract}

\section{Introduction}

Vertical profiles of wind speed and turbulence in the lower few hundred meters of the atmosphere are important, e.g., for the planning of high buildings, towers, and bridges and for the dispersion of air pollutants that are emitted or secondarily formed near the ground. Further, away from urban areas, these profiles have also become necessary for the design and siting of modern wind energy converters. The latest generation of these turbines has rotor diameters of up to $80 \mathrm{~m}$ and hub heights of about $100 \mathrm{~m}$.

For the first few tens of meters of the atmospheric boundary layer (ABL), the Prandtl-layer, a vast amount of data from the whole range of the frequency spectrum is available from in-situ measurements with cup and ultra-sonic anemometers. Within the Prandtl-layer this information can quite easily be converted into pro-

\footnotetext{
*Author's address: Stefan Emeis, Institut für Meteorologie und Klimaforschung, Atmosphärische Umweltforschung (IMK-IFU), Forschungszentrum Karlsruhe GmbH, Kreuzeckbahnstr. 19, 82467 Garmisch-Partenkirchen, Germany, e-mail: stefan.emeis@ imk.fzk.de
}

file data using the well-known similarity laws of the ABL. In flat terrain at about 50 to $80 \mathrm{~m}$ above ground the Prandtl-layer ends and the Ekman-layer with its characteristic turning of the wind begins. Apart from a few towers - most of them in level terrain - in-situ instruments cannot be placed in the Ekman-layer. The Prandtllayer similarity laws are not valid in the Ekman-layer. Therefore vertical profiles cannot be derived by expanding the Prandtl-layer profiles to greater heights. Remote sensing can be a solution to obtain Ekman-layer profiles. SODAR is most suitable for the lower part of the Ekman layer since acoustic remote sensing offers a good vertical resolution in the order of ten to thirty metres and a small lower detection height of some tens of metres. The boundary between the Prandtl- and the Ekman-layer is usually marked by a minimum of the diurnal variation of the wind speed. In the lower Ekman-layer wind speed is higher at night-time than at daytime, in the Prandtl-layer the wind speed maximum can be found during daytime.

A few tower measurements are available for urban areas. MANIER and BENESCH (1977) have evaluated mean wind speed profiles and power law exponents from 
towers in the German towns of Hamburg and Essen. They found that the power law exponents were slightly higher over urban areas than over rural areas indicating a rougher surface. Turbulence was not investigated. SEIFERT (2002) derived Weibull parameters also for the tower in Hamburg and found differences compared to the European wind atlas profiles (TROEN and PETERSEN 1990). The large vertical distances between the tower measurement heights do not allow an exact determination of the top of the Prandtl-layer.

Long-term SODAR measurements could clarify the following questions that are important for the climatology of the wind regime over a town:

a) how deep is the Prandtl-layer usually over an urban area?

b) how do wind and turbulence profiles over an urban area look like?

c) what is the diurnal and annual course of wind speed and turbulence intensity over a town?

Only one example of long-term SODAR wind measurements over an urban area is known in the literature: the studies of Lokoshchenko (see LOKOSHCHENKO (2002) and the references given therein) for the town of Moscow. But these measurements concentrated on the thermal structure of the ABL and the determination of the mixing layer height. No velocity profiles are reported from these measurements. Also for rural areas only a few long-term SODAR studies exist. Among these are the study on low-level-jets by JACOBI and ROTH (1995), the analysis of profiles of the variance of the vertical velocity component $\left(\sigma_{w}\right)$ by PETERS et al. (1998), the comparison of wind profiles and Weibull parameters over flat terrain and over a hill top in EMEIS (2001), and the study on the parameterization of mean wind and turbulence profiles by PETERS and FISCHER (2002). Here in the present paper a direct analysis of wind speed, $\sigma_{w}$, and turbulence intensity over an urban area will be presented as function of height, month, and time of the day.

\section{Methods}

The METEK DSD3x7 mono-static Doppler SODAR (REITEBUCH and EMEIS 1998) has three antennas with seven sound transducers (i.e. a device that serves both as a loudspeaker and as a microphone, depending on the phase of the measurement cycle) each, working at about $1500 \mathrm{~Hz}$. The instrument is optimised for longrange detection up to $1300 \mathrm{~m}$ above ground in ideal conditions without external noise sources. It returns vertical profiles of the acoustic backscatter intensity, the three components of the wind, and the variance of the vertical velocity component together with an estimate of the signal-to-noise ratio and an error code. One measurement cycle with operating all three antennas one after the other takes about 30 seconds. Thus, the variance contains the fluctuations on time scales between 30 seconds and the averaging period for the mean wind profiles (10 or 30 minutes, see below). A similar instrument has been used by PETERs et al. (1998) and PETERS and FISCHER (2002).

\section{Data}

Long-term meteorological and air quality measurements have been made in the surroundings of the street canyon "Göttinger Strasse" in the town of Hannover in Northern Germany. The SODAR has been placed about $550 \mathrm{~m}$ southwest of the street canyon on the grounds of a larger factory away from housing areas. This allowed a usual operation of the instrument without disturbing the inhabitants of the town. From October 2001 until April 2003 the SODAR has been run with one and the same settings. Within each hour two half-hour means were recorded. The first one uses the full range of the instrument (1200 $\mathrm{m}$ ) with a vertical resolution of $25 \mathrm{~m}$, the second one uses half of this range with double vertical resolution $(12.5 \mathrm{~m})$. Here only the high resolution data from the lowest $210 \mathrm{~m}$ above ground are used. Up to this height the availability of reliable SODAR wind data at this site has been more than $80 \%$ on the average. The horizontally averaged roughness length of the more or less urban area within a radius of $10 \mathrm{~km}$ is about $1 \mathrm{~m}$. The town of Hannover has a radius of about 7 to $8 \mathrm{~km}$, the measurement site is to the southwest of the town centre about $3 \mathrm{~km}$ from the periphery of the town. For June and July 2002 no data are available because the instrument was operated in another place. From the same data set an analysis of the mixing-layer height over the town of Hannover has recently be performed (EMEIS and TÜRK 2004).

Measurements with the same SODAR, taken from May 7 to May 30, 2003 at the military airfield of Fürstenfeldbruck about $25 \mathrm{~km}$ west of Munich, are additionally analysed here for comparison. The surroundings of the airfield are nearly flat with a few patches of forest. The overall roughness length within a circle of $10 \mathrm{~km}$ around the SODAR is about $10 \mathrm{~cm}$, the area more close to the SODAR has probably an even lower roughness of a few centimetres only. The lowest measurement height was $55 \mathrm{~m}$, the vertical resolution $30 \mathrm{~m}$, and the highest measurement height was $1285 \mathrm{~m}$. The temporal resolution was $10 \mathrm{~min}$. For the purpose of comparison with the Hannover data always 6 measurements have been averaged to form hourly means.

\section{Results}

Fig. 1 shows four examples for monthly mean vertical wind profiles between $35 \mathrm{~m}$ and $210 \mathrm{~m}$ above ground 

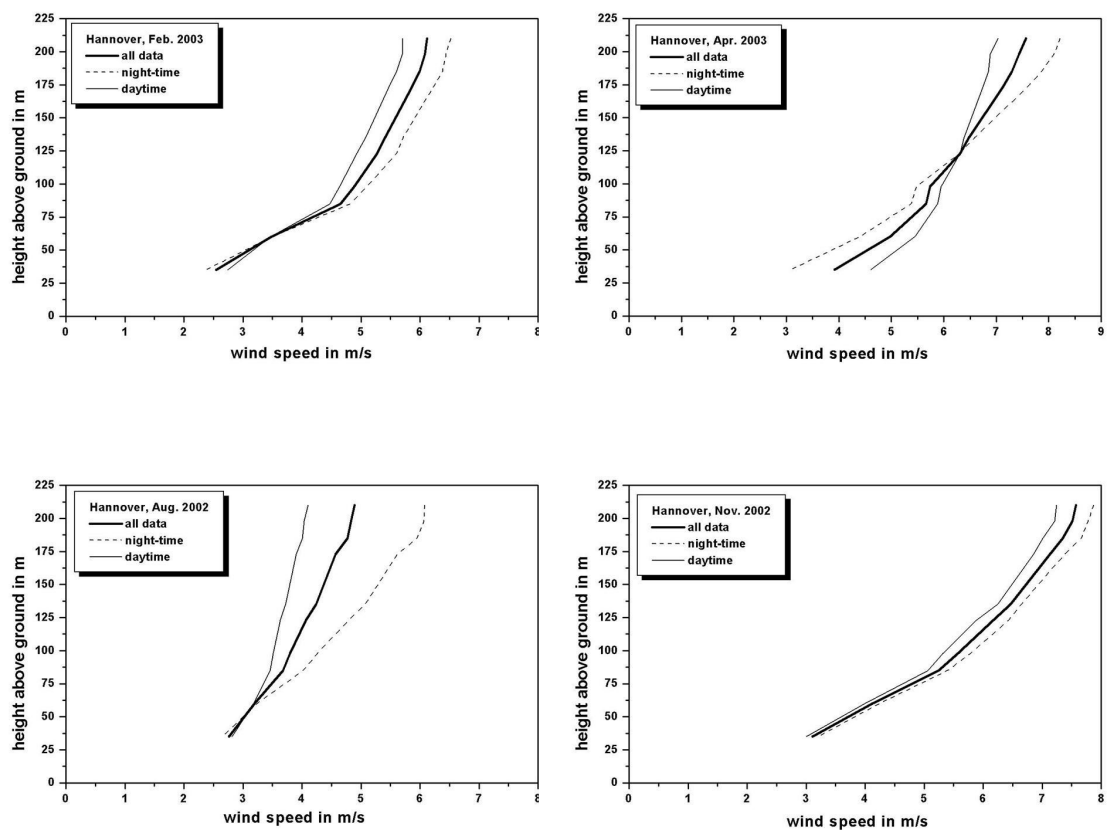

Figure 1: Monthly mean wind profiles in m/s for February 2003 (upper left), April 2003 (upper right), August 2002 (lower left), and November 2002 (lower right). Bold lines: all data, dotted lines: night-time data, thin lines: daytime data.
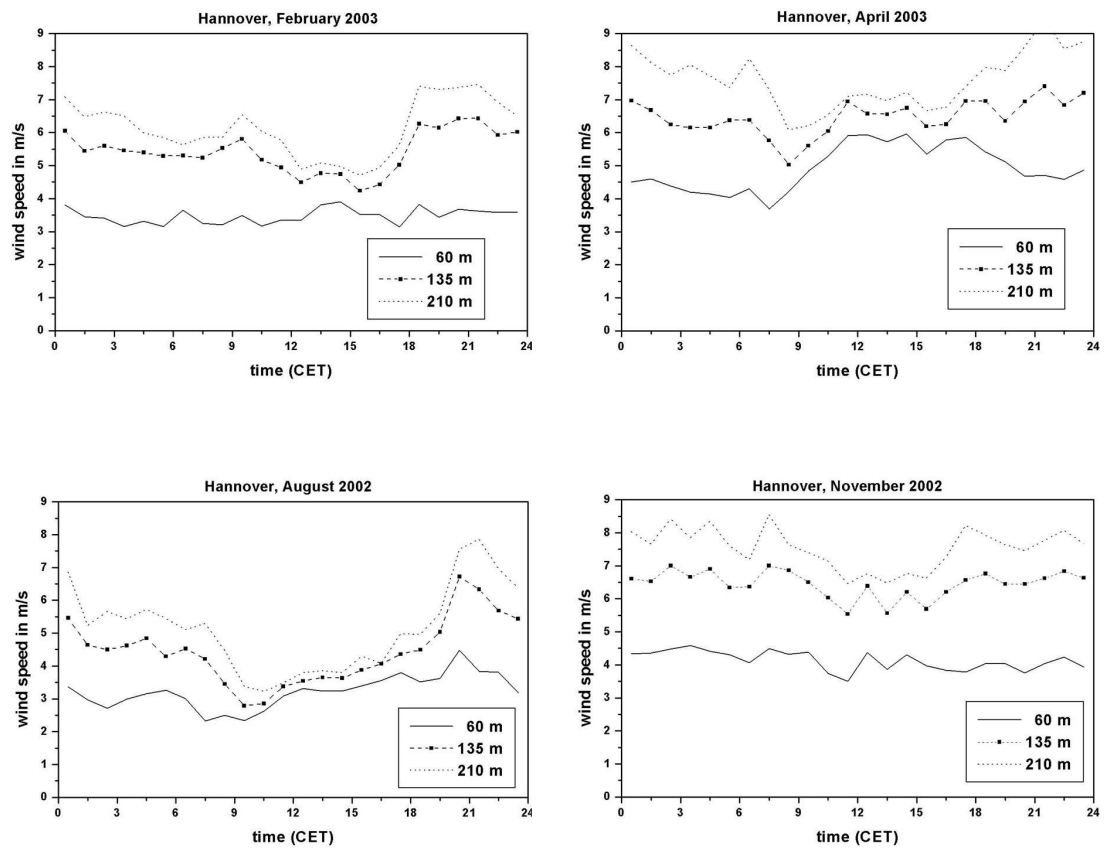

Figure 2: Monthly mean diurnal courses of wind speed in $\mathrm{m} / \mathrm{s}$ for three different heights (full lines: $60 \mathrm{~m}$ above ground level, dashed lines with marks: $135 \mathrm{~m}$ agl, dotted lines: $210 \mathrm{~m}$ agl) for February 2003 (upper left), April 2003 (upper right), August 2002 (lower left), and November 2002 (lower right).

for a very cold winter month (February 2003), a month in spring with a high number of clear days (April 2003), a month in summer with a high number of clear days (August 2002), and a windy autumn month (November 2002). For each of the four months the mean vertical profile from all data, the mean profile from night-time data (19 to 7 CET), and the mean profile from daytime data (7 to 19 CET) are given. In all four months the night-time winds are stronger than the daytime winds at larger heights. Only in April 2003 a typical cross-over of the profiles is found with stronger daytime winds at lower heights. Actually, April 2003 was the only month out of the 17 months of data from Hannover where such a distinct cross-over could be found. It should be kept 

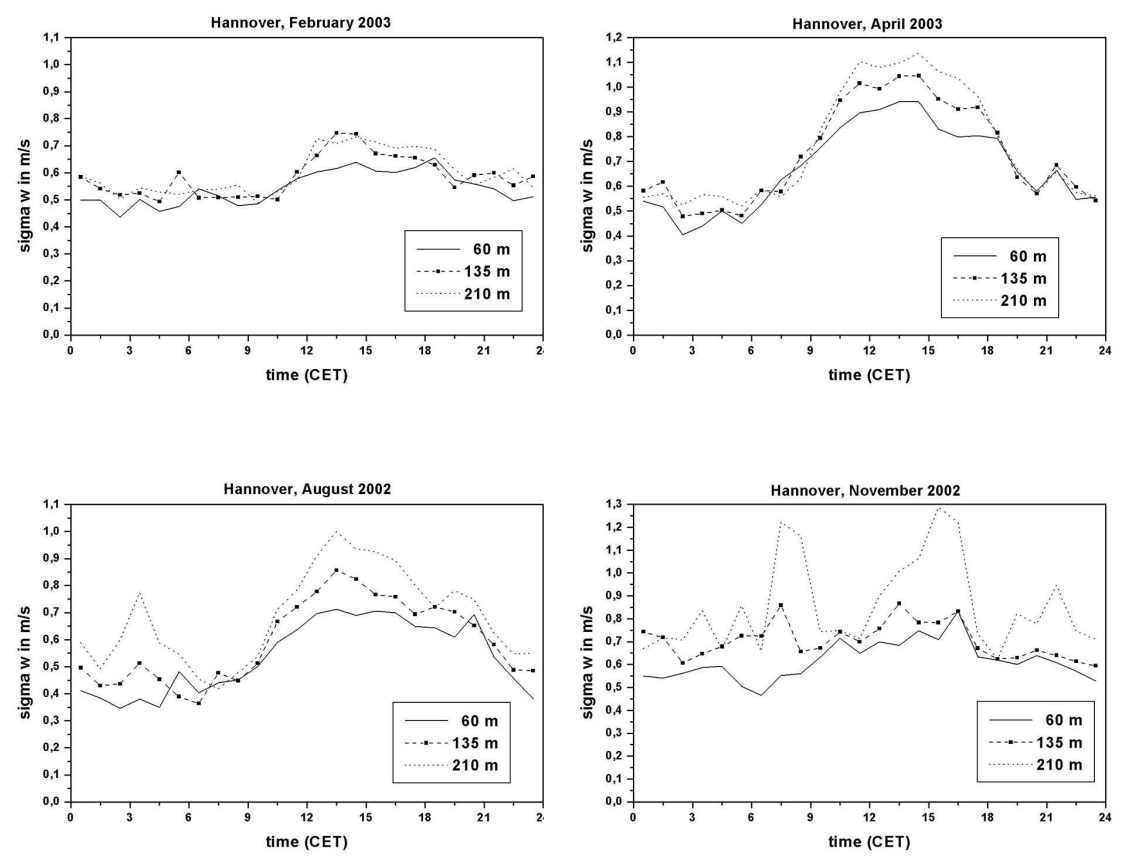

Figure 3: As Figure 2, but for $\sigma_{\mathrm{W}}$ in $\mathrm{m} / \mathrm{s}$.
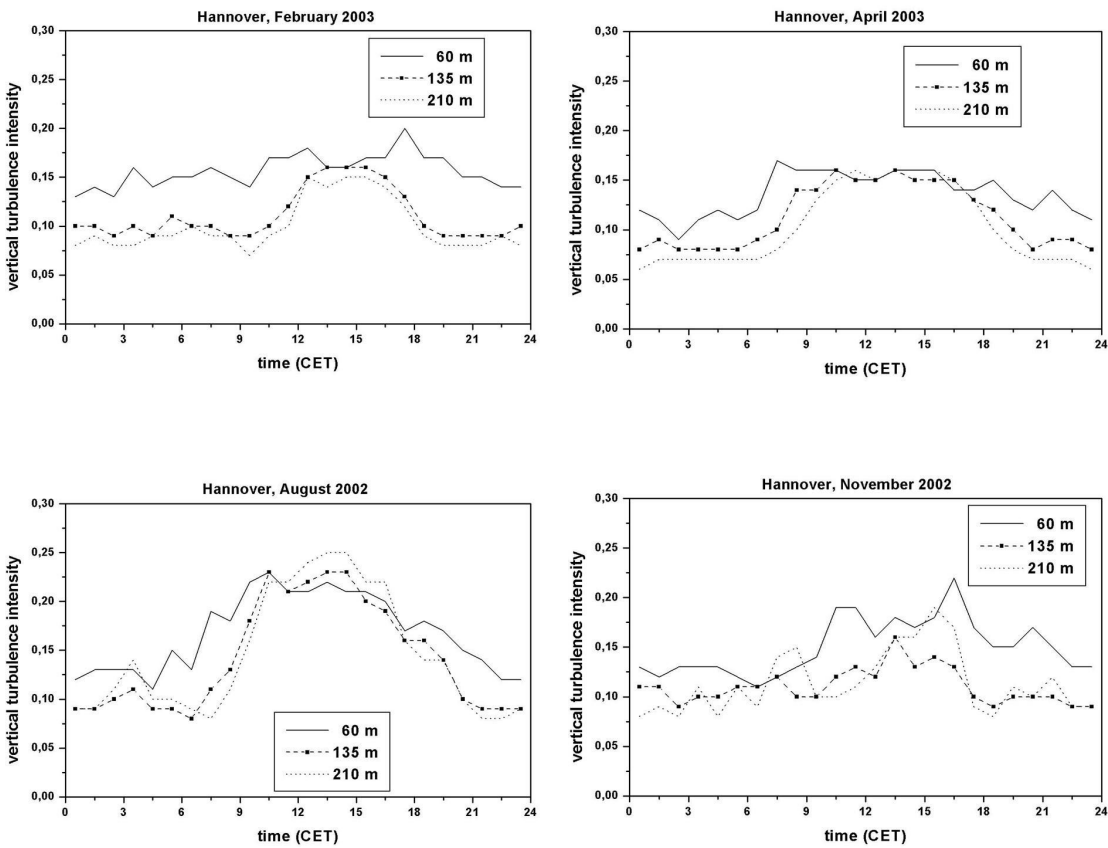

Figure 4: As Figure 2, but for $\sigma_{\mathrm{W}}$ divided by the mean horizontal wind speed.

in mind that there is considerable interannual variability, too. I.e., e.g., April 2002 and April 2003 look quite different.

The spread between daytime and night-time wind speeds is largest in summer, followed by spring, and then followed by the winter month. In the windy and cloudy November 2002 the spread nearly disappeared. The spread is an indication how much the turbulence intensity differs between daytime and night-time (see also Fig. 4 below).
Fig. 2 displays the mean diurnal course of the wind speed in the three selected heights 60,135 and $210 \mathrm{~m}$ agl. The lowest height usually is assumed to be in the Prandtl-layer, the other two in the Ekman-layer. With the exception of April 2003 a nearly constant wind speed is found during the whole day at $60 \mathrm{~m}$ height. In 135 and $210 \mathrm{~m}$ height the usual decrease of wind speed in the lower Ekman-layer around noon can be detected.

Fig. 3 presents the diurnal courses of the variance of the vertical wind component $\left(\sigma_{w}\right)$ in the same heights 

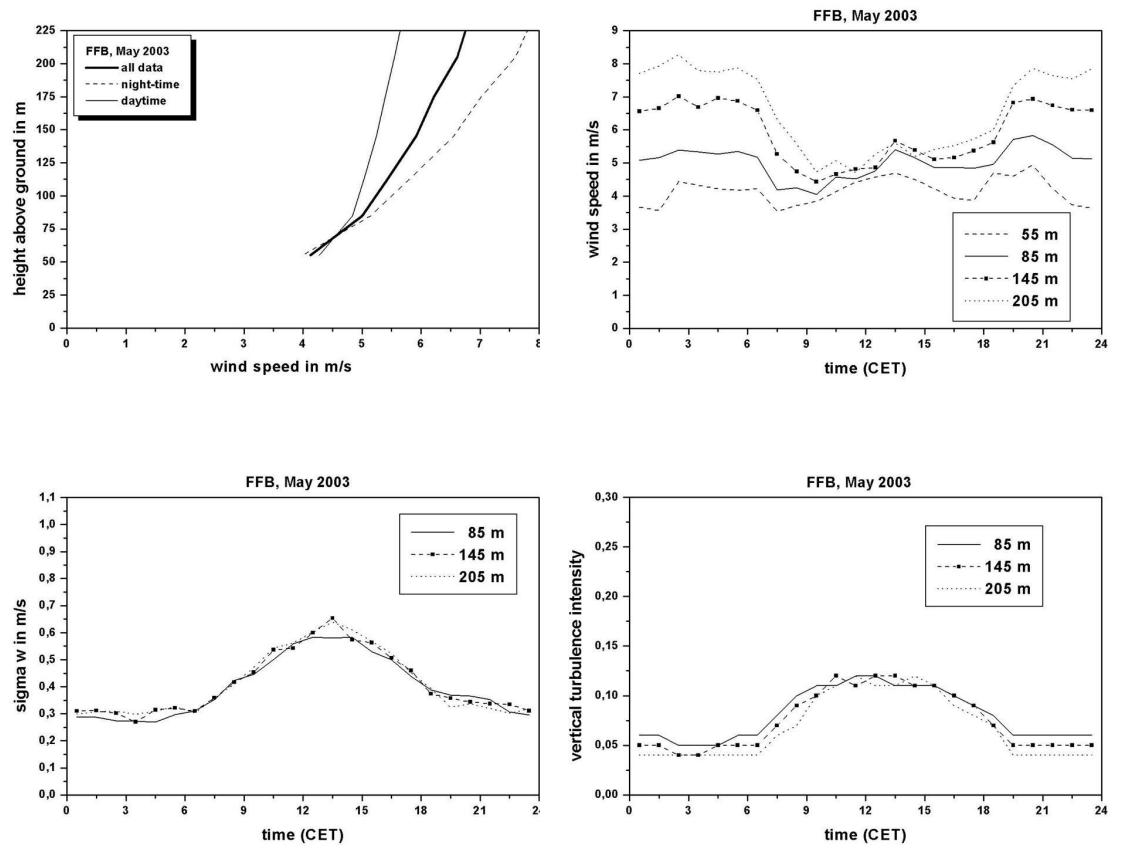

Figure 5: Mean wind profiles in $\mathrm{m} / \mathrm{s}$ (upper left), mean diurnal courses of wind speed in $\mathrm{m} / \mathrm{s}$ (upper right), mean diurnal courses of $\sigma_{\mathrm{W}}$ in $\mathrm{m} / \mathrm{s}$ (lower left), and mean diurnal courses of $\sigma_{w}$ divided by the mean horizontal wind speed (lower right) for level terrain on Fürstenfeldbruck air field in May 2003. Dashed line: $55 \mathrm{~m}$ above ground level, full lines: $85 \mathrm{~m}$ agl, dashed lines with marks: $145 \mathrm{~m}$ agl, and dotted lines: 205 $\mathrm{m}$ agl.

as those for which the wind speeds have been plotted before. Except for the windy November 2002 a clear diurnal course of $\sigma_{w}$ with lower values in the early morning hours and higher values in the afternoon is observed. This variance is shown here because it is the most direct turbulence information that can be deduced from Doppler SODAR measurements. The highest amplitude of the diurnal course is observed for April 2003. The daytime maximum of the variance is due to the large thermal production of turbulence because the shear production around noon is even less than during night (see reduced vertical wind speed gradient in Figs. 1 and 2). In November, no diurnal course of the turbulence can be analysed.

The variance is generally increasing with height, especially in August up to $350 \mathrm{~m}$ above ground and in November 2002 up to about $200 \mathrm{~m}$. This increase is strongest in the early afternoon as is expected for unstable stratification (see, e.g., STULL, 1988, equ. 9.6.3c). Such an increase for unstable stratification was also observed by PETERS et al. (1998). In August $2002 \sigma_{w}$ is also increasing with height at night. In February and April 2003 the variance is nearly height-independent at night-time as is expected for slightly stable stratification near the surface.

Because the variance $\sigma_{w}$ depends on wind speed (and surface roughness and thermal stratification) turbulence intensities $\sigma_{w} / \mathrm{U}$ are analysed, too. Fig. 4 shows the variance $\sigma_{w}$ displayed in Fig. 3 normalised by the wind speed $U$ shown in Fig. 2. This normalisation has been chosen because the friction velocity or the convective velocity scale, the quantities with which the velocity variances usually scale in the ABL, are not available from SODAR measurements. This vertical component of the turbulence intensity therefore has a diurnal course, which is strongest in August 2002 (see also the maximum spread in Fig. 1 for this month). Turbulence intensity is lowest at night and increases during daytime due to thermal production of turbulence. In November 2002, which was mainly overcast, the diurnal course is nearly absent. The turbulence intensity turns out to be highest for the $60 \mathrm{~m}$ level and then decreases with height. This decrease is smallest in the later afternoon. Typical nighttime values of the turbulence intensity for this measurement site (which does not seem to depend on the season) are 0.13 to 0.15 in $60 \mathrm{~m}$ agl, about 0.10 in $135 \mathrm{~m} \mathrm{agl}$, and 0.08 to 0.10 in $210 \mathrm{~m}$ agl. Shortly after noon this intensity reaches peak values around 0.17 to 0.25 depending on the season. Note that the night-time values in April 2003 are extremely low (upper right frame in Fig. 4).

The proof that these features are related to urban conditions can only be taken from a comparison to rural conditions. Fig. 5 therefore shows those profiles and curves, which have been presented in Figs. 1 to 4 for Hannover, for the airfield of Fürstenfeldbruck which is situated in a nearly flat area of Upper Bavaria for May 2003. The vertical profiles of the wind speed show a spread which is comparable to the spread of the daytime and night-time profiles in Hannover in August 2002. The cross-over of daytime and night-time profiles is found at 
about $70 \mathrm{~m}$. Unfortunately there were no measurements below $55 \mathrm{~m}$ in Fürstenfeldbruck. The diurnal course of the wind speed shows lower values during daytime and higher values at night-time at heights above $70 \mathrm{~m}$. In $205 \mathrm{~m}$ agl the nightly winds are nearly double as high as the daytime winds. The variance of the vertical wind component is nearly height-independent with values around $0.3 \mathrm{~m} / \mathrm{s}$ during night-time and peak daytime values around $0.7 \mathrm{~m} / \mathrm{s}$. The vertical component of the turbulence intensity is between 0.04 and 0.06 at nighttimes and peak values around 0.12 at daytime. The daytime peak values are rather low because days with the development of a convective boundary layer were not frequent in May 2003. Values in lower heights $(85 \mathrm{~m}$ agl) are only slightly higher than values at larger heights (205 m agl). Annual mean diurnal cycles of wind speed and $\sigma_{w}$ at a coastal site in flat marchland and at an extended forest area with gently rolling hills can also be found in PETERS and FISCHER (2002).

\section{Discussion and outlook}

For the first time, a Doppler SODAR has been operated for a longer term (17 months could be evaluated here) in an urban area. Profiles and mean diurnal courses of the horizontal wind speed, the variance of the vertical wind component, and of the vertical component of the turbulence intensity were derived. These profiles show some features that are obviously characteristic for an urban area.

Comparing the data for the urban area and for rural areas the following differences can be observed that answers questions $b$ ) and c) from the introduction:

1 The variances of the vertical velocity component are about $30 \%$ higher over the town than over the rural terrain west of Munich due to the higher surface roughness. A slightly smaller but similar difference between flat marshland and rough forest area has been found by PETERS and FISCHER (2002).

2 In the afternoon over the town the variance is increasing considerably with height, in summer up to about $350 \mathrm{~m}$ above ground, in winter up to about $200 \mathrm{~m}$. This feature is not found over rural terrain, neither in this study nor in the one by PETERS and FisCHER (2002).

3 In summer and autumn the variance is increasing with height even at night-time, which it does not over rural terrain (neither in the one month of data analysed here nor in the data analysed by Peters and Fischer (2002)).

4 The turbulence intensity is double as high over the town as over the rural terrain at night-time. This is mainly due to the enhanced variance because the mean wind speeds are not very much different.
5 The daytime increase in turbulence intensity seems to be larger over the town than over the rural terrain. This indicates a stronger heating of the urban surface.

6 The turbulence intensity is highest at $60 \mathrm{~m} \mathrm{agl}$ over the town, at night-time it is up to $50 \%$ larger than the turbulence intensity at 135 and $210 \mathrm{~m}$ agl. The nocturnal decrease of the turbulence intensity with height is much stronger over the town than over rural terrain.

7 The wind speed at $60 \mathrm{~m}$ agl is nearly constant all the day over the town (with the only exception of April 2003) whereas over the flat rural terrain it shows the usual increase around noon typical for the Prandtl-layer. A similar difference was found by PETERS and Fischer (2002): a near constant wind speed over the rough forest area but a daytime increase over the flat marshland.

The turbulence intensity can obviously be divided into two parts: a mechanically produced turbulence intensity and a thermally produced turbulence intensity. The mechanical part is the one which is present at nighttime. Its magnitude is determined by the roughness of the surface. The thermal stratification of the air does not seem to be very important for this mechanical turbulence production because the nocturnal turbulence intensity nearly does not depend on the season. The thermally produced part of the turbulence intensity is added to the mechanical part at daytime. This addition is the stronger the more incoming shortwave radiation there is. Large thermally produced turbulence is found not only over urban terrain but also over complex terrain with slopes facing the sun (EMEIS 2004).

The large turbulence intensity at $60 \mathrm{~m}$ agl, especially at night-time, is the reason for the more or less constant wind speed for all hours of the day in this height. This constancy indicates large vertical mixing also during night-time in this height that inhibits the thermal stabilisation and the decoupling of the flow. In April 2003 this decoupling could be observed because nocturnal turbulence intensities, and thus vertical mixing, were lower than average in this month. As this decoupling was observed only in one out of seventeen months it can be concluded that thermal decoupling in boundary layers over rough surfaces (towns, forests in rolling terrain) is a much more rare event than in boundary layers over flat terrain with low surface roughness.

Directly linked to the high turbulence intensities in the urban boundary layer is the missing of the cross-over of the mean daytime and mean night-time vertical velocity profiles. Over flat terrain with small surface roughness the height of this cross-over has proven to be a good indication for the boundary between the Prandtl-layer 
and the lower Ekman-layer (WIERINGA 1989). Thus, the question a) from the introduction (how deep is the urban Prandtl-layer) cannot be answered from the mean wind profiles.

Another indication for the top of the Prandtl-layer, especially at night-time could be a beginning decrease with height in turbulence intensity and the variance of the vertical velocity component. A variance constant with height or even increasing with height during the night is found. At least for the turbulence intensity a considerable decrease between $60 \mathrm{~m}$ and $135 \mathrm{~m}$ agl. is observed. Additional analysis shows that the vertical turning of the wind also starts within these two heights at night-time. So nearly $100 \mathrm{~m}$ could be a good guess for the height of the nocturnal urban Prandtl-layer.

During daytime, when a convective boundary-layer forms, no turning of the wind can be observed within the first $200 \mathrm{~m}$ above ground. Otherwise, the diurnal course of the wind speed shows a minimum during daytime in heights above about $100 \mathrm{~m}$. So, maybe the usual partition into Prandtl-layer and lower Ekman-layer is not very meaningful for a convective urban boundary-layer or even for a convective boundary-layer at all.

Points (2), (3), and (5) seem to be results that are specific for an urban boundary-layer. The other points probably hold for any boundary-layer over sufficiently rough surfaces. Therefore typical wind and turbulence profiles over an urban area are not just coined by the enhanced roughness but also by the thermal properties of the underlying surface. This surface becomes warmer during the day leading to the effects (2) and (3), and it stays warmer at night what might be the most probable reason for effect (5).

A further fact that has to be considered in studies on profiles in urban boundary-layers is the missing horizontal homogeneity of such boundary-layers. Usually, fetches are not long enough to guarantee homogeneity. The SODAR measurements analysed in this paper have been made just $3 \mathrm{~km}$ away from the periphery of the town with respect to the most frequent wind direction. But the definitions of a Prandtl-layer and an Ekmanlayer do depend on horizontal homogeneity. This would be an additional argument to rely more on vertical remote sensing than on similarity theories when assessing the vertical structure of an urban boundary-layer.

The evaluation of further SODAR measurements is planned. Data are presently available for another large town, for another place in open flat terrain and for two sites in orographically highly complex terrain. Further measurement campaigns are forthcoming. All this remote sensing information will contribute to a better understanding of wind and dispersion conditions in the lower Ekman-layer.

\section{Acknowledgements}

The measurements in Hannover were financed within the project VALIUM of the German Ministry of Education and Research (BMBF) under the framework program AFO2000. The measurements would not have been possible without the technical and scientific support from the Niedersächsische Landesanstalt für Ökologie (NLÖ), Hannover, and METEK GmbH, Elmshorn. Special thanks go to Mr. DRUNKENMÖLLE from NLÖ. We thank Komatsu Germany $\mathrm{GmbH}$ for the permission to use their grounds for the measurements. The measurements in Fürstenfeldbruck were funded within the project ICAROS NET of the 5th EU framework programme. We thank the German Air Force for the access to Fürstenfeldbruck air field and for their cooperation.

\section{References}

EMEIS, S., 2001: Vertical variation of frequency distributions of wind speed in and above the surface layer observed by sodar. - Meteorol. Z. 10, 141-149.

$\ldots, 2004$ : Parameterization of turbulent viscosity over orography. - Meteorol. Z. 13, 33-38.

EMEIS, S., M. TÜRK, 2004: Frequency distributions of the mixing height over an urban area from sodar data. - Meteorol. Z. 13, 361-367.

JACOBI, CH., R. RoTH, 1995: Organized meso-scale perturbations of the stably stratified planetary boundary layer. Meteorol. Z. 4, 150-161. (In German).

LokoshCHEnKo, M.A., 2002: Long-term Sodar Observations in Moscow and a New Approach to Potential Mixing Determination by Radiosonde Data. - J. Atmos. Oceanic Technol. 19, 1151-1162.

MANIER, G., W. BENESCH, 1977: Häufigkeitsverteilungen der Windgeschwindigkeit bis 250 m Höhe für die Bundesrepublik Deutschland. - Meteorol. Rdsch. 30, 144-152.

Peters, G., B. Fischer, 2002: Parameterization of wind and turbulence profiles in the atmospheric boundary layer based on sodar and sonic measurements. - Meteorol. Z. 11, 255-266.

Peters, G., B. Fischer, H.J. Kirtzel, 1998: One-year Operational Measurements with a Sonic AnemometerThermometer and a Doppler-Sodar. - J. Atmos. Oceanic Technol. 15, 18-28.

REITEBUCH, O., S. EMEIS, 1998: SODAR measurements for atmospheric research and environmental monitoring. Meteorol. Z., N. F. 7, 11-14.

SEIFERT, M., 2002: Windprognose für große Windkraftanlagen. - Erneuerbare Energien 12, Heft 7, 22-24.

STULL, R.B., 1988: An Introduction to Boundary Layer Meteorology. - Kluver Acad. Publ., Dordrecht, 666 pp.

Troen, I., E.L. Petersen, 1990: European Wind Atlas. - Meteorology and Wind Energy Dept., Ris $\varnothing$ Nat. Lab. Roskilde, Denmark.

WIERINGA, J., 1989: Shapes of annual frequency distributions of wind speed observed on high meteorological masts. - Bound.-Lay. Meteorol. 47, 85-110. 